\title{
A sustentabilidade da produção de óleos e manteigas vegetais em comunidade amazônica- RESEX Médio Juruá
}

The sustainability of vegetable oils and butters production in na amazonian community - RESEX

\author{
Médio Juruá
}

La sostenibilidad de la producción de aceites y mantecas vegetales em uma comunidade amazónicaRESEX Médio Juruá

\author{
Terena do Couto Sampaio Vidal \\ ORCID: https://orcid.org/0000-0001-7826-2201 \\ Universidade Federal do Amazonas, Brasil \\ E-mail: terenacouto@gmail.com \\ Maria Olívia de Albuquerque Ribeiro Simão \\ ORCID: https://orcid.org/0000-0002-8734-7714 \\ Universidade Federal do Amazonas, Brasil \\ E-mail: mariaoliviar@uol.com.br \\ Valdiney Ferreira de Almeida \\ ORCID: https://orcid.org/0000-0002-6817-9284 \\ Instituto Federal de Educação, Ciência e Tecnologia do Amazonas, Brasil \\ E-mail: valdiney.almeida@ifam.edu.br
}

\begin{abstract}
Resumo
Está cada vez mais evidente a importância do aproveitamento econômico da diversidade de produtos florestais, dentre eles os Produtos Florestais Não Madeireiros. A agregação de valores, a utilização de tecnologias adequadas às condições de exploração, o manejo florestal sustentável e o desenvolvimento de pesquisa apropriada, convergem em um plano mais estratégico na reestruturação da comercialização desses insumos vegetais. Neste trabalho é analisado o processo de produção de óleos e manteigas vegetais na Amazônia com vistas à sustentabilidade. Para tanto, foi realizado um estudo de caso na Usina de Extração de Óleos da Comunidade do Roque, localizada no município de Carauari, Amazonas, baseado na análise da dimensão ambiental do processo produtivo complementado por revisão teórica, pesquisa e análise descritiva. Os parâmetros analisados neste processo foram o manejo da vegetação nativa, o aproveitamento da matéria-prima e a destinação dos resíduos. Atualmente, as sementes processadas na Usina são das espécies de Andiroba, Murumuru e Ucuúba, coletadas em 51 Comunidades do Território Médio Juruá. Foi observado que o rendimento no processo industrial das sementes raramente excede a 30\%, 23\% e $43 \%$ respectivamente, do volume total de sementes processadas, o que gera grandes quantidades de resíduos. Os maiores custos para a produção do óleo e das manteigas são a aquisição de matéria-prima e a logística de distribuição. Além dessas dificuldades, os produtores ainda lidam com a sazonalidade da produção das espécies florestais, que em alguns anos rende mais matéria-prima e em outros não, impactando consequentemente os ganhos da Cooperativa responsável pela administração da Usina.
\end{abstract}

Palavras-chave: Produtos florestais não madeireiros; Processo produtivo; Comunidades rurais; Conservação do meio ambiente.

\begin{abstract}
It is increasingly evident the importance of the economic use of the diversity of forest products, among them the Non Timber Forest Products. The aggregation of values, the use of adequate technologies to the exploitation conditions, sustainable forest management and the development of appropriate research, converge in a more strategic plan in the restructuring of the commercialization of these vegetable inputs. In this work the production process of vegetable oils and butters in the Amazon is analyzed with a view to sustainability. For this, a case study was carried out at the Oil Extraction Industry of the Roque Community, located in the municipality of Carauari, Amazonas, based on the analysis of the environmental dimension of the production process complemented by theoretical review, research and descriptive analysis. The parameters analyzed in this process were the management of native vegetation, the use of raw materials and the destination of residues. Currently, the seeds processed in the industry are of the Andiroba, Murumuru and Ucuúba species, collected in 51 communities in the Médio Juruá Territory. It was observed that the yield in the industrial process of the seeds rarely exceeds $30 \%, 23 \%$ and $43 \%$ respectively, of the total volume of processed seeds, which generates large amounts of waste. The biggest costs for the production of oil and butters are the acquisition of raw materials and distribution logistics. Besides these difficulties, the producers still deal with the
\end{abstract}


seasonality of the production of forest species, which in some years yields more raw material and in others not, consequently impacting the earnings of the Cooperative responsible for managing the industry.

Keywords: Non-timber forest products; Productive process; Rural communities; Conservation of natural resources.

\section{Resumen}

Cada vez es más evidente la importancia de la explotación económica de la diversidad de productos forestales, entre ellos los productos forestales no madereros. La agregación de valores, el uso de tecnologías adecuadas a las condiciones de explotación, la gestión forestal sostenible y el desarrollo de una investigación adecuada, convergen en un plan más estratégico en la reestructuración de la comercialización de estos insumos vegetales. En este trabajo se analiza el proceso de producción de aceites y mantecas vegetales en la Amazonia con miras a la sostenibilidad. Para ello, se realizó un estudio de caso en la Industria de Extracción de Aceite de la Comunidad de Roque, ubicada en el municipio de Carauari, Amazonas, basado en el análisis de la dimensión ambiental del proceso productivo complementado con la revisión teórica, la investigación y el análisis descriptivo. Los parámetros analizados en este proceso fueron la gestión de la vegetación autóctona, el uso de la materia prima y el destino de las sobras. Actualmente, las semillas procesadas en la Planta son las especies de Andiroba, Murumuru y Ucuúba, recolectadas en 51 comunidades del Territorio Medio Juruá. Se observó que el ingreso en el proceso industrial de las semillas rara vez supera el 30\%, 23\% y $43 \%$ respectivamente, del volumen total de semillas procesadas, lo que genera grandes cantidades de residuos. Los mayores costes de la producción de aceites y mantequillas son la adquisición de materias primas y la logística de distribución. Además de estas dificultades, los productores siguen lidiando con la estacionalidad de la producción de las especies forestales, que en algunos años rinde más materia prima y en otros no, impactando consecuentemente en las ganancias de la Cooperativa responsable por la administración de la industria.

Palabras clave: Productos forestales no madereros; Proceso productivo; Comunidad rural; Conservación de los recursos naturales.

\section{Introdução}

O manejo de recursos florestais, dadas às características e potencialidades da região amazônica, se coloca como um dos principais caminhos para se alcançar um desenvolvimento com bases sustentáveis (Machado, 2008). O aproveitamento dos Produtos Florestais Não Madeireiros - PFNM têm se mostrado como alternativa que permite a diversificação econômica e a sustentabilidade da região.

Há um crescente interesse do mercado nacional e internacional por PFNM e a tendência é a concretização de práticas como a diversificação por meio do uso múltiplo de produtos da floresta. Esses produtos são de fundamental importância para manutenção de diversas populações tradicionais ou agroextrativistas e importantes recursos para remédios, alimentos e fontes de renda (Pedrozo et. al., 2011).

A agregação de valor a estes produtos, a utilização de tecnologias adequadas às condições de exploração, o manejo florestal sustentável, o desenvolvimento de pesquisa apropriada, a diversificação dos atuais sistemas de produção, aliado ao conhecimento da sociobiogeodiversidade, se tornam elementos fundamentais e estruturantes da bioeconomia na região amazônica e podem convergir em um plano mais estratégico na reestruturação da comercialização desses insumos vegetais (Freitas \& Schor, 2020). Baseado em dados da Comissão Europeia, a bioeconomia movimenta, na Europa, € 2,3 bilhões de euros e em 2016, segundo o mesmo estudo, o Brasil totalizou US\$ 326,1 bilhões em vendas atribuíveis à bioeconomia (PPA, 2019).

Dentro dessa perspectiva e considerando o estado do Amazonas possuir bioma de pouca intervenção humana, a bioeconomia deve estar atrelada à sustentabilidade socioambiental (Freitas \& Schor, 2020). Isso porque a produção ainda carece de avanço tecnológico que suporte o extrativismo sustentável com alto valor agregado no território das comunidades extrativas. Existe hoje na região uma série de atividades que fazem uso da biodiversidade Amazônica, porém, com pouco valor agregado (Sousa et. al., 2016). A maioria dos bioprodutos atualmente comercializados na Amazônia brasileira possui baixa densidade tecnológica e são comercializados como frutos in natura, ou apenas secos e descascados, óleo vegetal (sem purificação), com exportação que acontece principalmente em commodities. Para os autores, este aspecto torna o marketing referencial do bioma Amazônia um fator de agregação de valor. 
As indústrias de cosméticos (dermocosméticos), fitoterápicos e farmacêuticos (Enríquez, 2008) são setores da bioeconomia que demandam PFNM. Em termos relativos, o mercado brasileiro de cosméticos tem apresentado, nos últimos anos, crescimento constante, superando a própria dinâmica da economia nacional (Herculano, 2013). Todavia, não é fácil atribuir valor a esses produtos, menos ainda, valorar toda a cadeia de manejo sustentável de forma a atribuir preço justo ao produto final. Em toda a atividade que produz bens e serviços é necessário levar em consideração a maneira com que são utilizados fatores como terra, trabalho, capital, capacidade empresarial e recursos econômicos (Neves, 2016).

Muitas vezes a indústria utiliza como estratégia de marketing a origem e conservação do Bioma Amazônia como fator de agregação de valor em seus produtos. Neste contexto, a partir da análise de estudos sobre o manejo do extrativismo vegetal nas comunidades fornecedoras de matéria-prima para a Natura S/A, foi realizada pesquisa in loco concentrada na análise da sustentabilidade ambiental envolvida nos processos produtivos da Usina de Extração de Óleos e Manteigas Vegetais na Comunidade do Roque, localizada na Reserva Extrativista do Médio Juruá, município de Carauari, Amazonas. Essa Usina foi instalada em 1998 e desde 2003 sua produção abastece a empresa de cosméticos Natura S/A com o fornecimento do óleo de Andiroba (Carapa guianensis Aubl) e manteigas de Murumuru (Astrocaryum murumuru) e Ucuúba (Virola surinamensis (Rol.) Warb.).

\section{Metodologia}

\section{1 Área de estudo}

O estudo foi realizado na Usina de Extração e Beneficiamento de Óleos e Manteigas Vegetais, localizada na Comunidade do Roque (Figura 1), Município de Carauari, Estado do Amazonas, distante da capital Manaus $780 \mathrm{~km}$ em linha reta e $1.676 \mathrm{~km}$ por via fluvial (Brasil, 2011).

Figura 1: Localização da área de estudo, Comunidade do Roque, RESEX Médio Juruá, município de Carauari, Estado do Amazonas, Brasil.

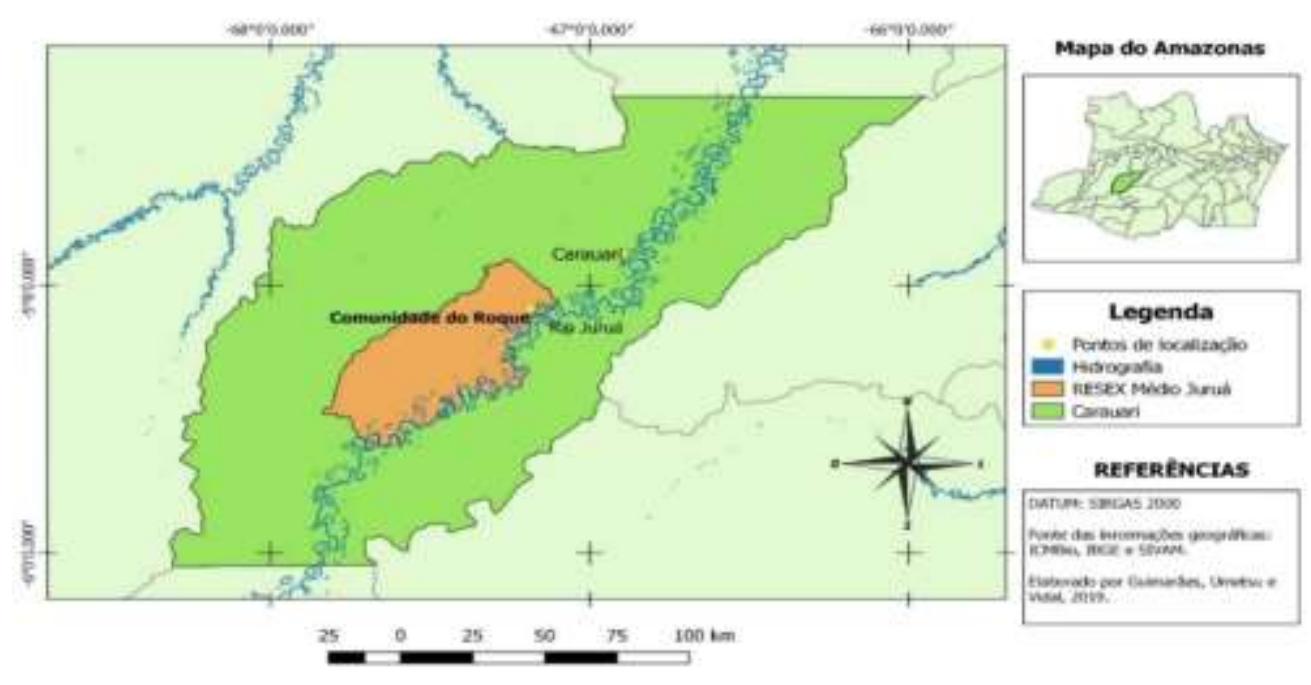

Fonte: Vidal e Guimarães (2018).

Este município possui uma área territorial de aproximadamente $25.778 \mathrm{~km}^{2}$ (IBGE, 2020) e localiza-se na região sudoeste do Estado do Amazonas, microrregião administrativa estadual $\mathrm{N}^{\circ} 02$, microrregião $\mathrm{N}^{\circ} 04$ do Vale do Rio Juruá e faz 
fronteira com os municípios de Juruá (ao norte), Jutaí (ao oeste), Itamarati (ao sul), Tefé e Tapauá (ao leste). A população estimada em 2019 foi de 28.294 habitantes.

Entre os anos de 1997 e 2005 foram implantadas na área rural do município duas Unidades de Conservação de Uso Sustentável, separadas pelo Rio Juruá. À margem direita, a RDS Uacari e à margem esquerda do rio, a RESEX do Médio Juruá.

A Comunidade do Roque ganhou destaque por ser escolhida em 1998 para implantação de projeto fruto de Convênio firmado entre o Programa do Trópico Úmido do Ministério da Ciência e Tecnologia - PTU/MCT, IBAMA, UFAM e COPPE/UFRJ, para geração de energia elétrica, substituindo o diesel por óleo vegetal. A Comunidade apresentava dificuldades de abastecimento de óleo diesel para geração de eletricidade e baixa renda da maioria dos habitantes, cenário muito comum em comunidades do interior da Amazônia (Andrade, 2010). A questão econômica acabou inviabilizando a ideia inicial levando a mudança no foco do projeto. Assim, a produção de óleo vegetal extraído na Usina começou a ser vendida para a empresa Natura Cosméticos S/A.

A Usina hoje é administrada pela Cooperativa de Desenvolvimento Agroextrativista e de Energia do Médio Juruá CODAEMJ e a comercialização dessa produção de óleos e manteiga vegetal representa uma das principais alternativas de renda para a população ribeirinha da região, principalmente nas áreas abrangidas pela RESEX do Médio Juruá e Reserva de Desenvolvimento Sustentável (RDS) Uacari.

\subsection{Procedimentos para coleta e análise dos dados}

Esta pesquisa é um estudo de caso, com abordagem qualitativa descritiva, utilizando múltiplas técnicas: observações em campo, entrevistas, pesquisa documental e bibliográfica. Sua trajetória permitiu uma ampla compreensão do processo produtivo da Usina de Extração de Óleos vegetais voltado para a indústria de cosméticos e suas implicações na realidade vivida na Comunidade do Roque (Pereira et. al., 2018).

Dois grupos participaram da pesquisa: (1) Presidente e representantes da CODAEMJ e (2) moradores da Comunidade, vale ressaltar que alguns deles são trabalhadores da Usina. As entrevistas foram realizadas com os representantes desses grupos em diferentes momentos. O local e momento das entrevistas dependeram da disponibilidade dos interlocutores tomando-se cuidado para não interferir na rotina da Comunidade. Conversas informais e observações diretas também fizeram parte das estratégias metodológicas. Essa observação permitiu um contato mais direto com os entrevistados.

A análise se concentrou na dimensão ambiental abrangendo critérios básicos da sustentabilidade, principalmente no que tange a capacidade desse sistema de produção e a operação na Usina, de se manter ao longo do tempo. Os parâmetros abordados foram: (1) Formas de manejo da vegetação nativa para produção de matéria-prima para extração de óleos vegetais; (2) Impacto do processo produtivo na Usina, adaptados dos parâmetros utilizados por Vasques (2014).

$\mathrm{Na}$ visita guiada a Usina do Roque utilizamos um check list descritivo que permitiu que enumerássemos e descrevêssemos as etapas do processo produtivo do empreendimento, elencadas a seguir: (1) Eficiência no uso de materiais, água e energia; (2) Geração e destino de resíduos sólidos; (3) Geração e destino de efluentes; (4) Existência/Substituição de produtos tóxicos; (5) Utilização de ferramentas para integrar o sistema de produção; (6) Divulgação de informações ambientais as partes interessadas (Cardoso, 2004).

Os dados foram tabulados e os resultados analisados utilizando o método de análise de conteúdo por categoria, conforme critérios delineados por Bardin (2014). 


\section{Resultados e Discussão}

A aquisição de matéria-prima para processamento na Usina de Extração de Óleos e Manteiga Vegetal da Comunidade do Roque foi uma das dificuldades identificadas. Para produção de 2018 (campo outubro de 2019), as sementes de Andiroba (Carapa guianensis Aubl), de Murumuru (Astrocaryum murumuru) e Ucuúba (Virola surinamensis (Rol.) Warb.) foram coletadas em 51 Comunidades do Território Médio Juruá distribuídas na RDS Uacari, na RESEX do Médio Juruá e no entorno dessas Unidades de Conservação.

Segundo os responsáveis da Cooperativa, nos meses de janeiro a agosto, membros da gestão da CODAEMJ e alguns cooperados viajam do Roque, onde está instalada a Usina até as demais Comunidades para fechar os Acordos de Compra da matéria-prima da nova safra e recolher a produção coletada e armazenada pelos comunitários (sementes de andiroba, ucuúba e murumuru) (Figura 2).

Figura 2: Esquema das atividades realizadas pela CODAEMJ.

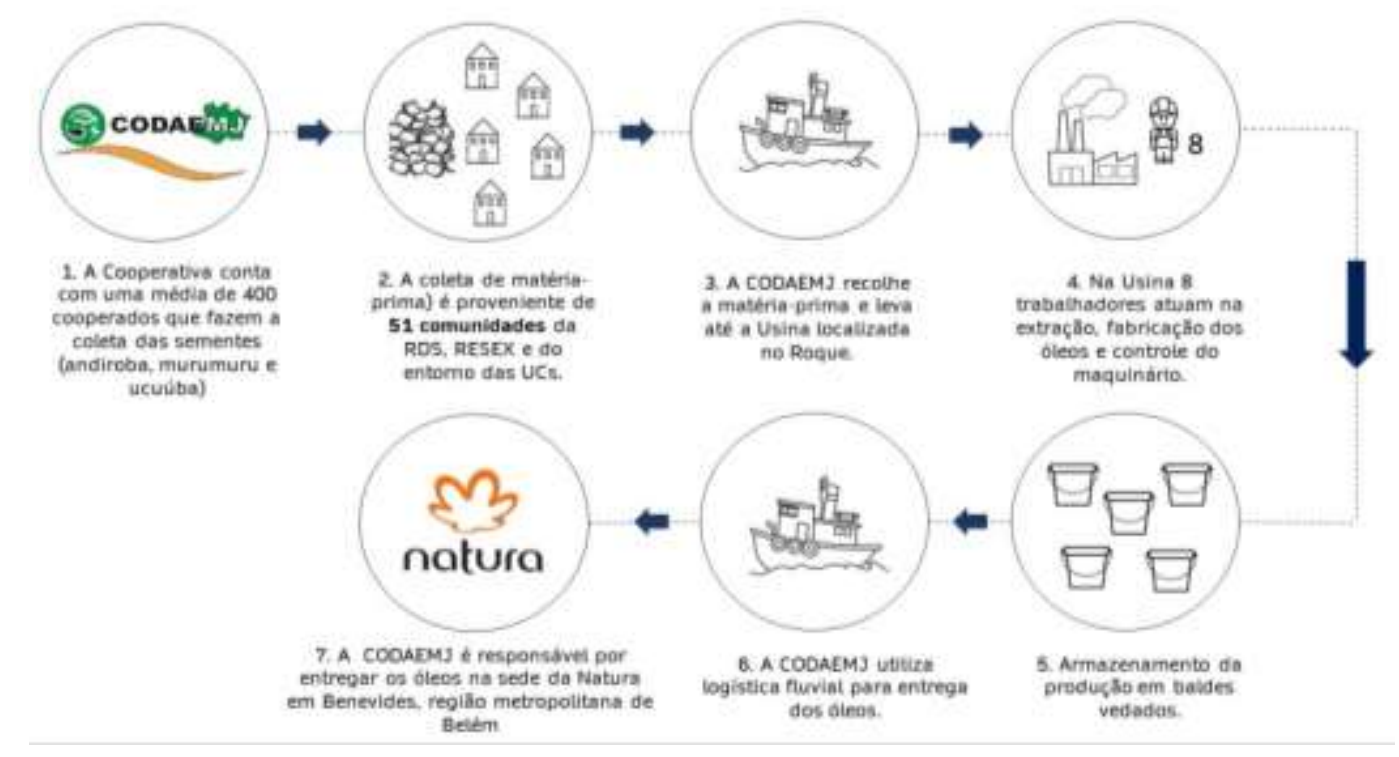

Fonte: Autores (2020).

O esquema acima detalha a trajetória da Cooperativa durante do ano produtivo, que começa com a entrega da produção estocada (safra anterior) e com o Acordo da nova safra firmado. Após, os coletores das comunidades iniciam a busca e coleta de sementes em diferentes períodos do ano correspondentes a safra de cada espécie. As coletas das sementes de Andiroba e Ucuúba ocorrem nos meses de janeiro a maio, enquanto a de Murumuru inicia no mês de junho e vai até meados de agosto. As sementes coletadas são estocadas nas comunidades até uma nova viagem da Cooperativa para captação da produção.

Diferente do relatado pelos entrevistados, estudos de Lourenço et. al, (2017) apontam que a época de produção de sementes de Andiroba vai de março a junho, com maior produção em maio, e em algumas localidades, a produção se estende até agosto. Ferraz, Camargo e Sampaio (2002), recomendam não coletar as sementes nos meses de dezembro a fevereiro (início da safra) e de julho a agosto (final da safra). Nesses períodos, a produção é muito baixa e essas sementes são importantes para a alimentação de alguns animais, que as espalham para outras partes da floresta, originando dessa forma, novas árvores. As sementes são coletadas embaixo das árvores mãe ainda dentro dos frutos ou soltas, de preferência logo após a dispersão. 
A Cooperativa informou que desde 2018 a coleta das sementes passou a abranger outras áreas, como as do município de Itamarati, Amazonas, isso porque nos últimos anos a safra na região do Médio Juruá foi menor do que a esperada, dificultando a entrega da produção acordada entre a empresa de cosmético e a Cooperativa.

Segundo dados da obtidos durante as entrevistas, quando a Usina foi inaugurada, quase todos os comunitários do Roque trabalhavam na coleta de sementes. Com o passar dos anos, com a dificuldade de se achar sementes próximas da Comunidade, tendo que ocorrer o deslocamento para áreas cada vez mais distantes, houve a diminuição da participação dos moradores da Comunidade nessa parte do processo produtivo.

O gestor informou que no ano de 2019 a demanda contratada de Andiroba e Murumuru foi de 15 toneladas. Segundo ele, neste ano a Cooperativa não conseguiu produzir a quantidade esperada pela falta de matéria-prima, entregando a empresa somente $60 \%$ da demanda contratada de óleo de Andiroba e 33\% de Murumuru. Neste ano não houve produção de Ucuúba. Segundo os cooperados, a safra de 2019 foi "ruim".

A sazonalidade da produção de frutos faz parte da autoecologia das espécies florestais. Segundo Lourenço et. al., (2017), as andirobeiras, por exemplo, podem tanto apresentar anos de baixa quanto de alta produção, ou até mesmo ficarem anos sem produzir quantidades significativas de sementes. A viabilidade ecológica, entretanto, ainda deve ser demonstrada à luz das preocupações sobre a produção intensiva com a possível abertura de novos mercados (Emperaire, Lescure \& Pinton, 1996). Deve-se, portanto, voltar à atenção para a análise de suas diferentes formas e das suas capacidades em adaptar-se a diferentes realidades produtivas. Assim, verifica-se ser de fundamental importância conhecer a distribuição temporal e espacial da produção dos frutos das espécies trabalhadas no perímetro de exploração com viabilidade econômica, propondo recomendações técnicas à cadeia produtiva dos óleos para a persistência populacional das espécies e garantia do negócio da Usina do Roque.

Hoje, a participação mais ativa dos comunitários do Roque está relacionada ao processamento, transporte, carregamento da matéria-prima de outras Comunidades até a Usina e do óleo e manteigas extraídos até o Porto de Carauari.

No Porto de Carauari a produção é colocada em uma balsa com destino a Manaus, onde esse carregamento é transportado até um Porto em Belém e por transporte rodoviário é entregue a uma Unidade produtiva da Natura S/A no município de Benevides, Região Metropolitana de Belém no Pará.

A logística de distribuição do óleo de Andiroba e das manteigas de Ucuúba e Murumuru é uma atividade que se dá de forma complexa. Para a entrega da produção a Cooperativa paga ao carregador (morador da comunidade) por balde de óleo (20 $\mathrm{kg}$ ) transportado da Usina até uma casa flutuante, localizada a beira do Lago do Roque (entrada da comunidade).

Do flutuante na beira do Lago, a produção passa para um barco fretado. Esse barco atraca no Porto de Carauari onde a produção é colocada em uma balsa com destino a Manaus. A cooperativa paga também o transporte de Manaus até Belém, que é cobrado por kg de óleo.

Apesar de o transporte hidroviário emitir quantidades reduzidas de poluentes, menos $\mathrm{CO}_{2}$ por TKU -tonelada por quilômetro útil-, ou seja, 80,2\% menos que o rodoviário e 14,2\% menos que o ferroviário, a produtividade da Usina do Roque é diretamente afetada pelas condições da infraestrutura desse transporte que é o único disponível para grande parte da região amazônica (CNT, 2019). Pode-se afirmar que quando essa infraestrutura apresenta melhorias em seu sistema, ocasiona o aumento da competitividade bem como garante a economia de escala e a redução dos preços das mercadorias (Macedo, 2012).

Na Região Hidrográfica Amazônica, somente em 2018, foi transportado um volume total de cerca de 63 milhões de toneladas e embora as vias navegáveis no Brasil sejam chamadas de hidrovias, o país não tem, de fato, hidrovias nos moldes que esse tipo de infraestrutura requer. A carência de manutenção das infraestruturas, entre outros aspectos, faz com que essas vias interiores ainda não atendam a todos os padrões de qualidade observados em hidrovias de referência em outros países (CNT, 2019). 
Segundo a Confederação Nacional de Transportes (2019), a existência desses entraves está relacionada a: "pouca atenção dada ao segmento nas políticas de Estado, à baixa efetividade dos planos e programas que contemplam o setor e aos reduzidos volumes de recursos destinados pelo Poder Público à melhoria das vias interiores."

Quando se discute a sustentabilidade de um processo produtivo, a definição comumente utilizada é a capacidade de um negócio conseguir manter-se ao longo dos anos, a partir de práticas financeiras e administrativas que preservem o meio ambiente e a manutenção dos recursos naturais. Neste contexto é importante entender os mecanismos utilizados no processo produtivo desde a obtenção da matéria prima, neste caso a extração de óleo de Andiroba e manteigas vegetais de Ucuúba e Murumuru.

\subsection{Infraestrutura e processo produtivo na usina do Roque}

Em 2019, o pátio produtivo de propriedade da CODAEMJ localizado na Comunidade do Roque era formado por máquinas, equipamentos e materiais utilizados no processamento e beneficiamento dos óleos e manteigas vegetais.

O mesmo maquinário é utilizado para o processamento das três espécies. Toda estrutura dos galpões é de madeira, exceto uma pequena casa de máquinas onde está instalado o gerador de energia a diesel.

As sementes chegam à Usina em sacos de $18 \mathrm{~kg}$ separados por lotes. Cada lote contém as informações dos coletores, data de coleta, quantidade de sementes $(\mathrm{kg})$, entre outras informações. A CODAEMJ organiza a rastreabilidade das safras em planilhas (Excel), dessa forma é possível ter um controle da quantidade que será produzida por matéria-prima, da perda por sementes estragadas e das datas de processamento.

Uma vez na Unidade de Processamento, as sementes trituradas são colocadas para aquecer a fim de facilitar a extração do óleo de Andiroba e das manteigas de Murumuru e Ucuúba. Na sequência as sementes trituradas e aquecidas são transportadas para a prensa onde é realizado o processo de prensagem para extração do óleo e das manteigas (Figura 3).

Figura 3: Fluxograma do processo produtivo na Usina de Extração de Óleo e Manteigas, Comunidade do Roque.

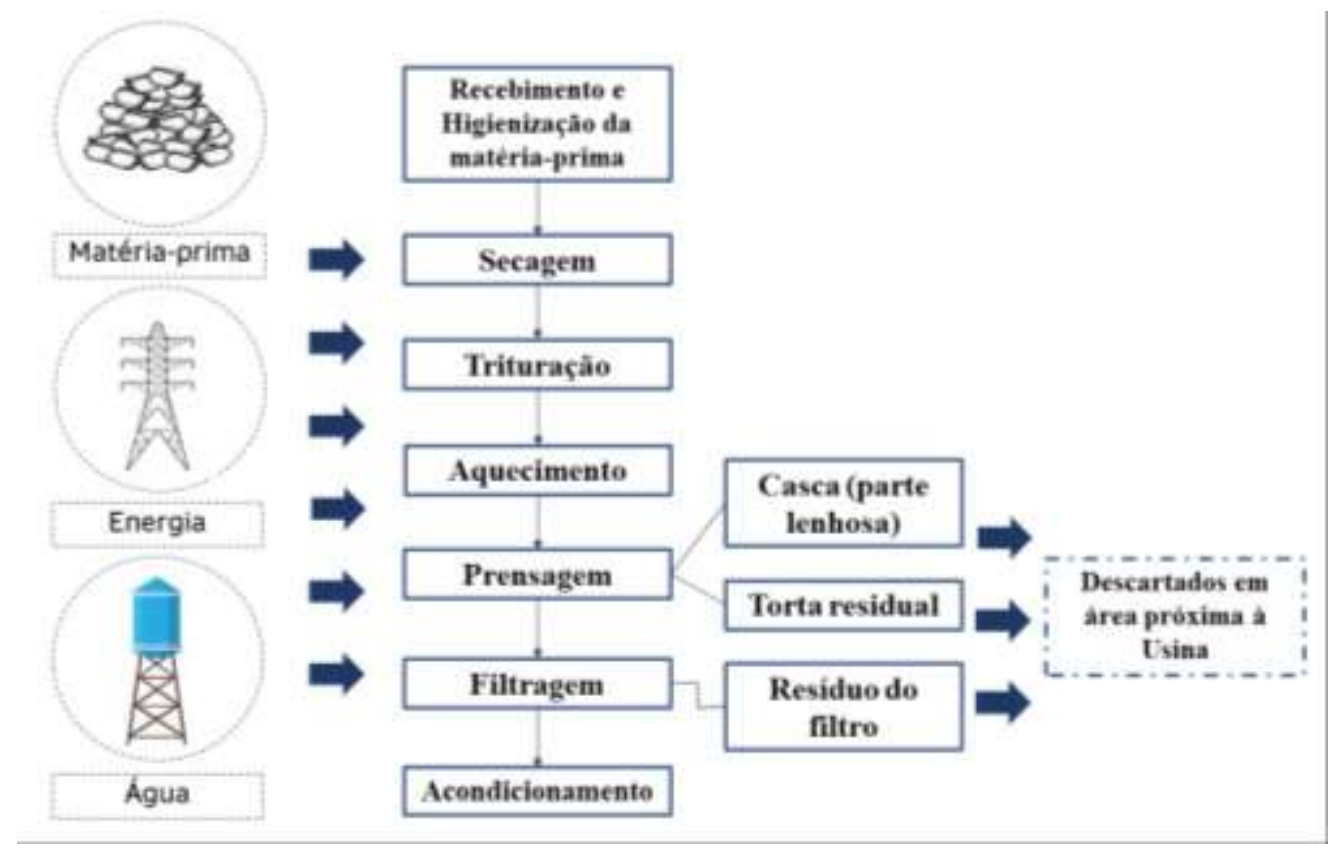

Fonte: Autores.

A figura acima descreve o passo a passo da produção dos óleos e manteigas assim que as sementes chegam a indústria. Após a prensagem, a etapa seguinte é a filtragem dos produtos. Ao saírem da prensa o óleo de Andiroba e as 
manteigas passam por um filtro, onde são retidas as partículas (finas). Por fim, o óleo e as manteigas são acondicionados em embalagens apropriadas (baldes vedados), pesados e armazenados para posterior distribuição. Não há durante o processamento da matéria-prima, para a fabricação dos óleos e manteigas, a utilização de produtos químicos ou tóxicos.

No processamento da Andiroba ocorre a secagem, aquecimento, trituração e prensa, e segundo o Presidente da Cooperativa, 1 lata de $12 \mathrm{~kg}$ de semente fresca de Andiroba é reduzida a $7 \mathrm{~kg}$ de semente depois de seca (a lata é a forma de medir o quantitativo das sementes coletadas pelos trabalhadores, é pesada com a semente ainda "verde", que não passou pelo processo de secagem).

Essa quantidade de semente seca produz cerca de $1,5 \mathrm{~kg}$ de óleo de Andiroba após o processamento. Esse valor condiz com a estimativa apontada por Ferraz (2003) onde o rendimento no processo industrial, ou seja, a quantidade de óleo extraída, raramente excede a $30 \%$ do peso das sementes de Andiroba.

Segundo informações de produção da Usina, o rendimento da Ucuúba é de cerca de $43 \%$ do peso total de sementes processadas. Em 2019, ano em que a pesquisa foi realizada não houve processamento da semente de Ucuúba, por falta de matéria-prima, as informações aqui descritas, desta espécie, foram retiradas dos dados de produção fornecidos pela Cooperativa.

O Murumuru também passa pela etapa de secagem, mas somente para soltar a amêndoa da "casca". Uma vez retirada a amêndoa, o próximo passo consiste na catação (separação da casca e da amêndoa) e trituração das para facilitar a posterior prensagem e o processo de extração da manteiga. Para se obter uma lata de amêndoas (12kg), já retiradas do coco, são necessárias três latas de Murumuru não beneficiado. Uma lata cheia de amêndoas produz 2,5 kg de manteiga de Murumuru. $\mathrm{O}$ rendimento do Murumuru é em média 23\% do volume total de sementes processadas.

Pode-se inferir então, que 60 a 80\% da matéria-prima beneficiada na Usina do Roque, é ineficientemente aproveitada e, portanto, descartada posteriormente como resíduo, que se acumula causando impactos ao meio ambiente (Figura 4). Este processo produtivo de extração gera três tipos de resíduos: (1) uma parte lenhosa proveniente das cascas das sementes; (2) a torta residual proveniente da prensagem; e (3) o resíduo gerado pela filtragem.

$\mathrm{Na}$ torta ficam concentradas as maiores quantidades de resíduos de todo o processo, cerca de 56\% para a Andiroba, 59\% para o Murumuru e 37\% para a Ucuúba. No momento da pesquisa, não foi verificado destino adequado aos resíduos gerados no processo produtivo. A parte lenhosa das sementes e a torta, por exemplo, são descartadas em uma área atrás da Usina do Roque.

Figura 4: Os resíduos da produção do óleo e das manteigas são dispostos em uma área atrás do galpão da Usina. A) Resíduos lenhosos da produção. B) Resíduo lenhoso e torta residual.
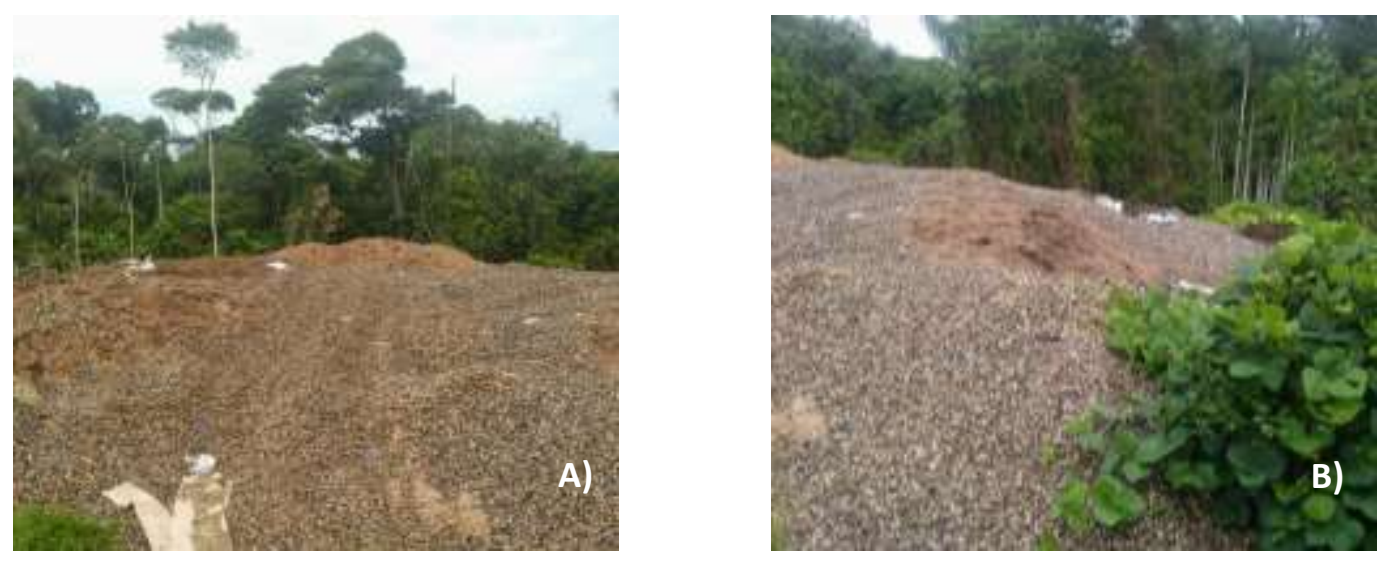
O material proveniente do processo, mesmo sendo biodegradável se constitui em material inflamável e descartado próximo a área da usina. Verifica-se o potencial de reaproveitamento desses resíduos para outros fins que além de diminuir o risco de acidente por incêndio e o impacto ao ambiente poderiam aumentar os lucros obtidos com a exploração mais eficiente da matéria-prima.

A torta residual gerada no processo de prensagem das sementes é rica em proteína e como é isenta de solventes tóxicos, pode ser usada como adubo ou ração animal, mas esse uso não acontece na Comunidade. Essa torta é descartada no solo, em área localizada atrás da Usina, e ainda contém certa quantidade de óleo, e principalmente no caso da Andiroba, origina um produto altamente inflamável.

Alguns estudos demonstram que a torta de Murumuru também pode ser utilizada para suplementação alimentar de outros animais, mostrando-se como alternativa em até $20 \%$ de substituição em dietas para ovinos e em níveis de até $40 \%$, constitui boa alternativa a ser introduzida na formulação de dieta nos sistemas de produção de ruminantes (Morais et. al., 2013; Menezes, 2012).

Segundo Pimenta e Azevedo (2020), a economia extrativista e agroextrativista tem a capacidade de ser muito mais eficiente se beneficiada com mais conexões, por exemplo, com mercados que queiram esses produtos, com tecnologia adequada, conhecimento para agregar valor às cadeias sociobiogeodiversidade e com o crescimento de um processo industrial de última geração que usa tecnologias inteligentes muito menos intensivas em energia. Como o modelo de economia circular, onde os materiais retornam ao ciclo produtivo e não são descartados como resíduo, por meio da logística reversa, com a reutilização, recuperação e/ou reciclagem dos materiais. Segundo Machado et. al. (2020), a economia circular está no topo da agenda política e possui o sentido de promover o crescimento econômico por intermédio da criação de novos produtos, oportunidades de emprego e a redução dos impactos ambientais.

A região Amazônica possui elevado potencial nesse sentido. Ribeiro e Kruglianskas (2015) indicam, por exemplo, que 90\% do material extraído do meio natural se tona resíduo antes mesmo dos produtos saírem das indústrias. Santos (2014) afirma que o aumento da industrialização de matéria-prima nativa da região gera um número crescente de resíduos muitas vezes descartados. Para o autor se forem empregadas tecnologias adequadas, este material pode ser convertido em produtos comerciais ou matérias-primas para processos secundários como alimentos para animais, fertilizantes, velas repelentes (caso da Andiroba), combustível ou ainda serem reaproveitados para a obtenção de substâncias bioativas.

A Cooperativa tem buscado parcerias para a implementação de uma alternativa viável para utilização dos resíduos provenientes do processo industrial. É desejável, sempre que possível, que o resíduo final dos processos produtivos se constitua em subproduto para um novo processo, favorecendo uma nova transformação.

O apoio aos negócios comunitários (associações e cooperativas) tais como o realizado pela CODAEMJ deve ser uma prioridade das políticas públicas por se tratar de um alvo de investimento para os negócios privados que querem gerar mais impacto social em suas cadeias de fornecedores. Fortalecendo a cadeia, há a resiliência social e econômica dessas comunidades. Gerando assim, o fortalecimento desses negócios comunitários de impacto socioambiental que se tornam estratégicos para o desenvolvimento de uma bioeconomia mais inclusiva (Pimenta \& Azevedo, 2020).

Foi observado durante a pesquisa que não existe a adoção de uma política de divulgação de informações e boas práticas ambientais para todos os agentes da cadeia produtiva. No modelo produtivo da Usina não há metas ambientais ou mesmo relatórios ambientais escritos a respeito das atividades industriais realizadas. Apesar de a CODAEMJ ser bem organizada dentro dos limites que eles possuem, faltam pessoas que entendam de gestão de negócios para ajudá-los nessas questões e na melhoria do plano de negócio. A Cooperativa consegue fazer um bom trabalho na área produtiva, porém com a ajuda de especialistas em gestão econômica e ambiental, os entraves acima descritos poderiam ser minimizados. 
Nesse contexto, é importante destacar que durante muitos anos a produção a nível industrial, pouco se preocupou com os impactos ambientais que suas atividades acarretavam, acreditava-se que crescimento econômico, por si só, proporcionaria melhores condições de vida para a sociedade (Werner, Bacaraji \& Hall, 2009). Embora algumas evoluções tenham ocorrido nos modos de produção, a economia sempre se pautou em um modelo linear de extração, fabricação, uso e descarte. Nesta lógica, desenvolvida pelo modelo "fordista" de produção aplica-se trabalho e energia para que os recursos naturais sejam extraídos, beneficiados e convertidos em produtos, que por sua vez são comercializados, utilizados e ao final do processo tudo que resta é descartado como resíduo. Fordismo é um termo que se refere ao modelo de produção em massa de um produto, ou seja, ao sistema das linhas de produção (Ribeiro \& Kruglianskas, 2015).

No entanto, o entendimento que o crescimento econômico desenfreado, causa danos irreparáveis ao ecossistema e do aumento da conscientização da população que passou a exigir da indústria a adoção de produtos potencialmente menos poluidores, fez emergir modelos de produção voltados aos ideais de sustentabilidade (Oliveira, França \& Rangel, 2019). Iniciase a partir de então, um processo de busca por melhorias nos procedimentos e produtos que possibilitassem uma melhor utilização dos recursos naturais e pela redução nos resíduos industriais e domésticos (Lopes, 2015).

Tomando por base que a Usina do Roque exerce uma atividade industrial, é essencial o planejamento adequado de processos por meio de ações que resultem no prolongamento da vida útil dos produtos ali fabricados e que esses sejam livres de desperdícios e/ou efeitos danosos ao meio ambiente. Isso traria valores agregados ao processo. Além disso, validaria ainda mais o conceito de conservação ambiental do seu principal comprador, que é uma empresa que preza pela sustentabilidade e é detentora de várias certificações ambientais. Encontrar a sinergia entre progresso e preservação do meio ambiente é uma necessidade cada dia mais difundida, presente em indústrias e empresas que necessitam manterem-se competitivas no mercado, aumentar produtividade, reduzir perdas e ainda reduzir ao máximo o impacto que sua produção causa ao ambiente e a sociedade em geral (Cavicchioli \& Gasparotto, 2019).

\subsection{Os insumos utilizados na produção da usina}

No processo produtivo, a água utilizada na Usina é proveniente de um poço artesiano que também abastece as casas na Comunidade do Roque. A água é armazenada em uma caixa d'água de 500 litros, quantidade suficiente para atender a demanda necessária para 3 (três) dias de produção.

O poço foi construído por intermédio de um projeto intitulado: "Sanear Amazônia: mobilização social por acesso a água às famílias extrativistas na Amazônia" que tinha como objetivo promover acesso a água para o consumo humano em comunidades extrativistas da Amazônia. O projeto é uma proposta que assegura o abastecimento de água potável para 2.800 famílias extrativistas de forma direta. A ampliação do projeto ocorreu em 2014, a partir da articulação política do CNS (Conselho Nacional dos Seringueiros) com o MDS (Ministério do Desenvolvimento Social), iniciando um processo de sistematização de tecnologias sociais de saneamento rural para a Amazônia, com base nos modelos de tecnologias implementados no projeto piloto, junto ao Programa Cisterna do MDS (Bernardes, Costa \& Bernardes, 2018).

Quanto a energia, é advinda da Usina Termoelétrica de Carauari que utiliza óleo diesel e possui o fornecimento muito instável. Quando há interrupção, o que acontece com bastante frequência, devido à rede de distribuição para as Comunidades ser precária, é utilizado um gerador instalado na Usina que também é alimentado por óleo diesel. Mesmo com falta de abastecimento de energia da Rede de Carauari, a conta da Empresa de energia fica em média de $\mathrm{R} \$ 1.000,00 / \mathrm{mês}$.

O óleo diesel é o combustível mais utilizado nessas áreas isoladas para geração de energia elétrica. É encontrado principalmente em centrais termelétricas, regiões isoladas da rede elétrica e indústrias que utilizam grupos geradores para equipamentos e/ou veículos que necessitam de grande potência (Udaeta et. al., 2004). Desta forma, existe uma crescente 
preocupação quanto à exposição aos gases e vapores liberados pelos equipamentos que utilizam motores a diesel como fonte de energia, uma vez que os produtos da sua exaustão são prejudiciais tanto à saúde humana quanto ao meio ambiente.

Em 2019 a Usina não trabalhou com a energia distribuída pela Termoelétrica de Carauari, considerando que o maquinário necessita de fornecimento trifásico e somente duas fases estavam funcionando. Assim, durante todo o período da safra daquele ano foi utilizado o gerador a óleo diesel. Esse tipo de imprevisto influenciou fortemente nos custos de produção diminuindo o lucro obtido pelos cooperados.

Segundo relatos, quando precisam usar o óleo, gastam em média 50 litros de diesel/12 horas de trabalho/dia. Na época de plena produção, a Usina funciona de 12 a 13 horas/dia, 26 (vinte e seis) dias por mês. Assim, na safra de 2019 o custo aproximado com óleo diesel foi de $\mathrm{R} \$ 245,00 /$ dia (valor do diesel à época da pesquisa estava $\mathrm{R} \$ 4,90$ ), gerando um custo aproximado de $\mathrm{R} \$ 50.960,00$ (cinquenta mil novecentos e sessenta reais) nos 8 (oito) meses de produção na Usina (março a outubro/2019).

A baixa densidade demográfica e o espaçamento das comunidades inseridas na área rural da Amazônia dificultam e encarecem o acesso à energia. Além disso, há ainda o preço elevado do combustível, que é um grande obstáculo para o transporte tanto de pessoas quanto de mercadorias. Essa dura realidade acarreta baixa rentabilidade da atividade produtiva $\mathrm{e}$ causa sérias dificuldades econômicas para os moradores do interior amazônico, que permanecem na pobreza e na exclusão social (Di Lascio, 2009).

Apesar de não ser possível comparar os produtores do Roque com as grandes indústrias de cosméticos, é importante levantar a questão da mudança de conceito e organização dos pequenos produtores rurais. A Usina precisa melhorar seu processo produtivo e entender o sistema econômico em que seus produtos estão inseridos: mercado sustentável, mercado verde. Isto permite iniciar ações que possibilitam a melhoria dos processos visando a certificação de sua produção. Para que isso ocorra efetivamente, é necessária a organização da atividade para se programar e executar processos de ajustes e acompanhamento do processo produtivo. Neste aspecto ação de Universidades e órgãos de assistência técnica governamental são muito importantes.

Considerando a realidade desses produtores que estão nas Comunidades do Médio Juruá, em uma RESEX que tem como premissa a exploração dos recursos naturais de forma sustentável, entende-se que, ao se melhorar o processo produtivo, melhorarão também os ganhos econômicos dos cooperados envolvidos na extração de óleos e manteigas vegetais, de manutenção e manejo das fontes de matéria-prima e das condições de cada um dos setores que fazem parte da cadeia produtiva.

Dessa forma, é importante iniciar discussões sobre: planejamento, administração, custos de produção, eficiência, competição, ganho, rentabilidade, excedente de produção e lucro (Holanda Junior, 2020). Neste sentido, destacamos alguns instrumentos potenciais de operacionalização para a bioeconomia amazônica, como: Produção mais limpa; Ecoeficiência; Ecologia Industrial; Economia Circular; Bolsa de Mercadorias da Amazônia (Werner, Bacaraji \& Hall, 2009; Silva, Souza \& Costa, 2015; Leitão, 2015; Ometto, Amaral, Iritani, 2018; Mascarenhas, 2019; Oliveira, França \&; Rangel, 2019; Freitas \& Schor, 2020).

Esses novos modelos podem vir a subsidiar propostas para a inserção da Usina do Roque como unidade fabril sustentavelmente ambiental e também obter certificação de responsabilidade social, entre outras. Neste contexto, a Produção Mais Limpa, por exemplo, propõe aplicação continuada de uma estratégia ambiental preventiva e integrada aos processos e produtos, a fim de aumentar a eficiência e reduzir os riscos à sociedade e ao meio ambiente, além de minimizar os desperdícios, reduzir custos, e alavancar o potencial inovador da organização, visando ganhos de competitividade (Werner, Bacaraji \& Hall, 2009). Outro exemplo que poderia ser aproveitado é o programa de Ecoeficiência, em que o processo de produção é monitorado e são identificadas todas as fontes de uso de água, energia e materiais, em que poderão estar ou não 
ocorrendo desperdícios ocultos, com consequente aumento no gasto de água e energia e incremento na geração de resíduos sólidos, efluentes líquidos e emissões atmosféricas. Esses desperdícios estão relacionados a fatores como problemas operacionais, qualidade de materiais e à falta de procedimentos e de treinamento adequado das equipes (Torres, 2019).

A Economia Circular identifica cinco setores prioritários para acelerar a transição ao longo das cadeias de valor (plásticos, resíduos alimentares, matérias-primas essenciais, construção e demolição, biomassa e materiais de base biológica) (Sintra, 2019). Nela o processo produtivo sustentável se dá em circuito fechado, otimizando o uso dos recursos e possibilitando que haja ciclos contínuos de reconversão (Oliveira, França \& Rangel, 2019).

Freitas e Schor, (2020) apontam a importância de implementar a Bolsa de Mercadorias da Amazônia como um instrumento financeiro para o desenvolvimento sustentável, trata-se de uns mercados onde vendedores e compradores se reuniriam para negociar os produtos da sociobiodiversidade, com a garantia de qualidade, entrega e pagamento, utilizando instrumentos como contratos padronizados, unidades de recebimento e armazenamento de produtos estrategicamente posicionados. Fomentando, dessa forma o desenvolvimento sustentável e justo e erradicando a pobreza entre as populações produtoras e extrativistas.

Nesta perspectiva vemos que nesta atividade podem ser idealizados novos mecanismos de produção ao longo do ciclo de extração dessas espécies, além dos óleos e manteigas, aproveitando inclusive os resíduos que hoje são totalmente desperdiçados. Como verificado, os resíduos produzidos na Usina poderiam até servir de biomassa para produção de energia mais limpa, uma vez que a fonte de energia que hoje abastece a Usina é altamente poluidora, de origem da queima de combustíveis fósseis. Os produtos e subprodutos poderiam ser diversificados e as melhorias podem abranger todo o ciclo, da fabricação ao consumo, passando pela gestão dos resíduos, novos produtos, certificações.

Mas, tudo isso tem um custo e a Cooperativa já trabalha com ganhos muito reduzidos e necessitaria de ajuda técnica para planejar e instituir esses mecanismos sem inviabilizar o negócio que tem na aquisição de matéria-prima e nos custos de transporte para escoamento da produção seus maiores gastos.

$\mathrm{Na}$ indústria cosmética que compra o óleo de Andiroba e as manteigas de Murumuru e Ucuúba já são adotados mecanismos rígidos de conservação e sustentabilidade ambiental que compõem a cadeia de valor dos cosméticos produzidos o que inclusive impõe diferencial em seus produtos e lhes confere certificações ambientais. Porém, ainda não estão totalmente presentes no processo de extração que ocorre na Usina do Roque. A implantação destas metodologias pressupõe inovação, incremento competitivo e responsabilidade socioambiental, uma vez que tais processos preveem em sua origem, a manutenção dos ecossistemas, a prevenção da poluição, a busca do crescimento e o desenvolvimento econômico sustentável.

Neste sentido, a empresa compradora, que consome os óleos e manteigas extraídos na Comunidade do Roque, poderia assegurar a sustentabilidade em todos os elos da cadeia de valor de seus produtos se a Usina adotasse medidas de sustentabilidade em seu processo produtivo. Essa empresa tem know-how e capacidade técnica que, em parceria com outras instituições, poderiam ser oferecidos a CODAEMJ para a melhoria dos processos produtivos na Usina do Roque, e de forma direta, a toda a cadeia de valor dos cosméticos produzidos com esses insumos (óleos e manteigas) com agregação de valor.

O termo "agregação de valor" acima mencionado faz referência às estratégias de divulgação que são adotadas quando se quer exaltar algo oriundo de produtos florestais não madeireiros, a partir da introdução de inovações tecnológicas nos processos extrativos e produtivos, associada à valorização da origem e das formas tradicionais de exploração desses produtos (Diniz et. al., 2013).

O empoderamento dos extrativistas e produtores poderia servir de base para a reestruturação do modelo de produção adotado na Usina do Roque, a fim de tornar toda cadeia de produção condizente com os princípios da sustentabilidade. Outra vantagem em se adotar técnicas mais sustentáveis, é a manutenção do valor ao produto final, os cosméticos produzidos com esses insumos, já que o consumidor final estaria consumindo produtos elaborados com o óleo de Andiroba ou as manteigas de 
Murumuru e Ucuúba de uma cadeia sustentável do início ao fim. Neste processo o esforço da Cooperativa em melhorar os processos produtivos da Usina para uma postura ambientalmente correta, mesmo em condições pouco favoráveis, seria um diferencial no processo produtivo.

\section{Conclusão}

A produção da Usina do Roque é ambientalmente insustentável. Não há tratamento nos resíduos gerados que são estocados em um terreno atrás da Usina. Há também o uso de uma grande quantidade de óleo diesel na geração de energia para o funcionamento das máquinas no processo produtivo, uma fonte de energia altamente poluidora, de origem da queima de combustíveis fósseis.

Não há, por parte das agências governamentais ou da empresa compradora dos óleos e manteigas, incentivos para a adoção de mecanismos de produção mais limpa, evitando dessa forma desperdícios e otimizando o processo produtivo.

Apesar dos representantes da Cooperativa informarem que a retirada da matéria-prima é inferior a capacidade de suporte das espécies, as safras oscilam muito causando incertezas das quantidades de óleos e manteigas a serem produzidas, o que pode levar ao rompimento e estagnação da atividade.

É necessária a adoção de medidas para torná-la uma atividade ambientalmente sustentável. Assim, poderiam ser idealizados novos mecanismos de produção ao longo do ciclo de extração dessas espécies que poderiam ir além dos óleos e manteigas, aproveitando inclusive os resíduos que hoje são totalmente desperdiçados.

Na produção poderiam ser adotadas medidas de melhoria do ciclo de vida dos produtos, da fabricação ao consumo, passando pela gestão dos resíduos e o mercado das matérias-primas secundárias.

A adoção desses princípios na cadeia de valor dos cosméticos produzidos pode inclusive dotar de diferencial seus produtos e lhes conferir certificações ambientais. Porém, ainda estão totalmente ausentes na origem da matéria-prima, no processo de extração que ocorre na Usina do Roque.

A implantação destas metodologias pressupõe custos, inovação, incremento competitivo e responsabilidade socioambiental, uma vez que tais processos preveem em sua origem, a manutenção dos ecossistemas, a prevenção da poluição, a busca do crescimento e o desenvolvimento econômico sustentável.

Os resultados aqui apresentados ampliam a base de conhecimento sobre a temática, induzindo novos debates sobre a questão, gerando subsídios à elaboração de políticas públicas de desenvolvimento regional, bem como o estímulo a outros estudos no escopo dos processos produtivos que utilizam a grande riqueza que se constitui a sociobiogeodiversidade amazônica.

Como proposta para futuras pesquisas, sugere-se a adoção de técnicas mais sustentáveis para agregação de valor ao produto final, assim os cosméticos produzidos com esses insumos fariam parte de uma cadeia sustentável do início ao fim.

\section{Referências}

Andrade, C. S. (2010). Energia elétrica e as populações tradicionais do Estado do Amazonas: aprendizados a partir da experiência na Comunidade do Ro que na Reserva Extrativista do Médio Juruá. Tese de Doutorado. Universidade Federal do Rio de Janeiro.

Bardin, L (2014). Análise de Conteúdo: Edições 70.

Bernardes, R. S., Costa, A. A. D. \& Bernardes, C. (2018). Projeto Sanear Amazônia: tecnologias sociais e protagonismo das comunidades mudam qualidade de vida nas reservas extrativistas. Desenvolvimento e Meio ambientes. Edição especial: 30 Anos do Legado de Chico Mendes V. 48. DOI: 10.5380/dma. v48i0.58510.

Brasil. (2011). Instituto Chico Mendes da Biodiversidade. Plano de Manejo da Reserva Extrativista do Médio Juruá. http://www.icmbio.gov.br/portal/unidadesdeconservacao/biomasbrasileiros/amazonia/unidades-de-conservacao-amazonia/2036-resex-medio-jurua.

Cardoso, L. M. F. (2004). Indicadores de produção limpa: uma proposta para análise de relatórios ambientais de empresas. Dissertação de Mestrado. Universidade Federal da Bahia. 
Cavicchioli, A. F. \& Gasparotto, A. M. S. (2019). Uma análise de interação entre os sistemas de produção Lean Manufacturing e Produção Mais Limpa. SIMTEC - Simpósio de Tecnologia da Fatec Taquaritinga, 5(1).

CNT. Confederação Nacional do Transporte. (2019). Aspectos gerais da navegação interior no Brasil. Brasília. https://cnt.org.br/aspectos-gerais-navegacaobrasil.

Di Lascio, M. A; et. al. (2009). Energia e desenvolvimento sustentável para a Amazônia rural brasileira: eletrificação de comunidades isoladas. Ministério de Minas e Energia. https://agritrop.cirad.fr/567794/1/solucoes_energeticas_para_a_amazonia.pdf

Diniz, J. D. A. S. et. al. (2013). Agregação de valores a espécies do Cerrado como oportunidade de inserção da agricultura familiar em mercados diferenciados. Via Sapiens (Difusão IEPE/UGRGS). pp. 268-289.

Emperaire, L., Lescure, J. P. \& Pinton, F. (1996). O povo e os produtos florestais na Amazônia central: uma abordagem multidisciplinar do extrativismo.

Enríquez, G. E. V. (2008). Desafios da Sustentabilidade na Amazônia: Biodiversidade, Cadeias Produtivas e Comunidades Extrativistas Integradas. Tese de Doutorado. Universidade de Brasília.

Ferraz, I. D. K. (2003). Andiroba, Carapa guianensis Aubl. Informativo Técnico Rede de Sementes da Amazônia. N. 1. https://www.inpa.gov.br/sementes/iT/1_Andiroba.pdf

Ferraz, I. D. K. \& Camargo, J. L. C., Sampaio, P. T.B. (2002). Sementes e plântulas de andiroba (Carapa guianensis AUBL. E Carapa procera D. C.): aspectos botânicos, ecológicos e tecnológicos. ACTA AMAZÔNICA.

Freitas N. F. \& Schor, T. (2020). Bioeconomia e a Bolsa de Mercadorias da Amazônia: Uma Iniciativa Inovadora Para o Desenvolvimento Sustentável da Região Amazônica. Interesse Nacional - edição especial 01 - BIOECONOMIA. Instituto Escolhas, 2020

Herculano, F. E. B. (2013). Produção Industrial de Cosméticos: o protagonismo da biodiversidade vegetal da Amazônia. Tese de Doutorado. Universidade Federal do Amazonas.

Holanda Junior, E. V. (2020). Árvore do conhecimento: ovinos de corte. Gestão de Unidade Produtiva. Agência Embrapa de Informação Tecnológica. Brasília. https://www.agencia.cnptia.embrapa.br/gestor/ovinos_de_corte/arvore/CONT000fwf8r72302wyiv807fiqu9a5u410t.html.

IBGE, (2020). Instituto Brasileiro de Geografia e Estatística. (2020). Censo 2020. https://www.ibge.gov.br/cidades-e-estados/am/carauari.html.

Leitão, A. (2015). Economia Circular: Uma Nova Filosofia de Gestão Para O Século XX. Portuguese Journal of Finance, Management and Accouting, 1(2).

Lopes, R. H. (2015). A inserção de agricultores familiares em cadeias, produtivas globais: Um estudo da produção de óleo de buriti (Mauritia flexuosa) na Comunidade Santo Antônio do Abonari. Tese de Doutorado. Universidade Federal Amazonas.

Lourenço, J. N. P. et. al. (2017). Produção, biometria de frutos e sementes e extração do óleo de andiroba (carapa Guianensnis Aublet. Sob manejo comunitário em Parintins, AM. Embrapa Amazônia ocidental.

Macedo, C. S. (2012). Infraestrutura de transporte hidroviário de carga no estado do Amazonas: um diagnóstico a partir das políticas públicas de investimentos. Dissertação de Mestrado. Universidade Federal do Amazonas.

Machado, et. al. (2020). Economia Circular e Resíduo de Pescado. Revista Brasileira de Ciências Ambientais, 55, (4), 2176-9478.

Machado, F. S. (2008). Manejo de Produtos Florestais Não Madeireiros: um manual com sugestões para o manejo participativo em comunidades da Amazônia.

Mascarenhas, J. M. G. A. (2019). Bioplásticos e plásticos biodegradáveis surfando a sexta onda: um estudo sobre a ecoeficiência. Revista Valore (Edição especial). Volta Redonda. DOI: https://doi.org/10.22408/reva402019359133-142

Menezes, B. P. (2012). Consumo, digestibilidade, balanço de nitrogênio e composição bromatológica da torta de murumuru (Astrocaryum murumuru var murumuru mart) na alimentação de ruminantes. Dissertação de Mestrado. Universidade Federal do Pará.

Morais et. al. (2013). Produção de leite e consumo concentrado em búfalas lactantes suplementadas com concentrado à base de torta de cupuaçu (Theobroma grandiflorium) e torta de murumuru (Astrocaryum murumuru). Anais do X Congresso Brasileiro de Buiatria. Pará.

Neves, N. A. S. (2016). Ensino da Economia Através do Estudo da Cadeia Produtiva do Artesanato de Bio e Eco Joias no município de Tabatinga no Amazonas. Tese de Doutorado. Universidade Federal Rural do Rio de Janeiro.

Oliveira, F. R., França, S. L. B. \& Rangel, L. A. D. (2019). Princípios de economia circular para o desenvolvimento de produtos em arranjos produtivos locais. INTERAÇÕES. Campo Grande. 20(4). DOI: http://dx.doi.org/10.20435/inter.v20i4.1921

Ometto, A. R., Amaral, W. A., \& Iritani, D. R. (2018). Economia circular: oportunidades e desafios para a indústria brasileira. Confederação Nacional da Indústria. - Brasília: CNI, 2018

Pedrozo, E. A. et. al. (2011). Produtos Florestais Não Madeiráveis (PFNMS): as Filières do Açaí e da Castanha da Amazônia. Revista de Administração e Negócios da Amazônia, 3(2). https://www.periodicos.unir.br/index.php/rara/article/view/201/234.

Pereira A. S., Shitsuka, D. M., Parreira, F. J. \& Shitsuka, R. (2018). Metodologia da pesquisa científica. UFSM. https://repositorio.ufsm.br/bitstream /handle/1/15824/Lic_Computacao_MetodologiaPesquisa-Cientifica.pdf?sequence=1

Pimenta, C. \& Azevedo, A. (2020). Por Uma Bioeconomia Inclusiva e Que Mantenha Em Pé a Floresta. Interesse Nacional - edição especial 01 BIOECONOMIA. Instituto Escolhas. 
Research, Society and Development, v. 10, n. 3, e32710313478, 2021

(CC BY 4.0) | ISSN 2525-3409 | DOI: http://dx.doi.org/10.33448/rsd-v10i3.13478

PPA, Parceiros Pela Amazônia. (2019). Bioeconomia: uma chave de desenvolvimento potente e sustentável para a Amazônia. https://ppa.org.br/2019/11/29/bioeconomia-uma-chave-de-desenvolvimento-potente-e sustentavel-para-a-amazonia/.

Ribeiro, F. M. \& Kruglianskas, K. (2015). A Economia Circular no contexto europeu: Conceito e potenciais de contribuição na modernização das políticas de resíduos sólidos. Universidade de São Paulo.

Santos, M. J. T. (2014). Aproveitamento de resíduos da indústria de óleos vegetais produzidos na Amazônia. Dissertação de Mestrado. Universidade Federal do Pará.

Silva, T. P., Souza, S. A. \& Costa, M. N. (2015). Produção mais limpa: eficiência ambiental na produção das indústrias de cerâmica vermelha em Guanambi Bahia. XXXV ENCONTRO NACIONAL DE ENGENHARIA DE PRODUCAO. Perspectivas Globais para a Engenharia de Produção. Ceará.

Sintra, P. V. (2019). Jornada técnica sobre Economia Circular. Prémios Humana Circular. http://m.smartwasteportugal.com/fotos/editor2/jorn ada_economia_circular_programa_provisorio.pdf

Sousa, K. A. et. al. (2016). Bioeconomia na Amazônia: uma análise dos segmentos de fitoterápicos e fitocosméticos, sob a perspectiva da inovação. Fronteiras: jornal of social, technological and environmental Science, 5(3).

Torres, F. A. (2019). Ecoeficiência em operações de empresas pelo uso de geração distribuída fotovoltaica. Dissertação de Mestrado. Escola de administração de empresas de São Paulo, São Paulo.

Udaeta, M. E. M. et. al. (2004). Comparação da produção de energia com diesel e biodiesel analisando todos os custos envolvidos. Enc. Energ. Meio Rural. GEPEA-USP, Grupo de Energia do Departamento de Engenharia de Energia e Automação Elétricas da Escola Politécnica da Universidade de São Paulo.

Vasquez, M. S. (2014). Sustentabilidade agrícola na comunidade ilha das flores- São Gabriel da Cachoeira, Amazonas. Tese de Doutorado. Universidade Federal do Amazonas.

Werner, E. M., Bacaraji, A. G. \& Hall, R. J. (2009). Produção Mais Limpa: Conceitos e Definições Metodológicas. In: Simpósio de Excelência em Gestão e Tecnologia. Anais do SEGETC.https://www.aedb.br/seget/arquivos/artigos09/306_306_PMaisL_Conceitos_e_Definicoes_Metodologicas.pdf 